\title{
Equilibrative nucleoside transporter 1 (slc29a1) localization on vaginal epithelial cells
}

Paul Webster ${ }^{1 *}$, John Cortez ${ }^{1}$, Simon Webster ${ }^{1}$, Manjula Gunawardana ${ }^{1}$, Richard B. Pyles ${ }^{2}$ and Marc M. Baum

*Correspondence: p.webster@oak-crest.org

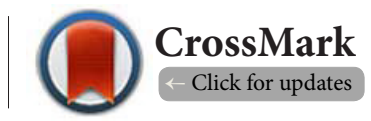

'Oak Crest Institute of Science, 132 W. Chestnut Ave, Monrovia, CA 91016.

2University of Texas Medical Branch, 301 University Blvd., Galveston, TX 77555-0436, USA.

\begin{abstract}
Background: The equilibrative nucleoside transporter 1 (ENT1), a protein encoded by the SLC29A1 gene, is able to carry nucleosides across cell membranes. The high affinity for adenosine makes it relevant to anti-retroviral therapy (ART), where the drugs are adenosine analogs. The ENT1 protein might transport adenosine drug analogs such as tenofovir (TFV) and its prodrugs into and out of cells, removing them from their site of action.

Methods: A commercial polyclonal antibody to the ENT1 protein was applied to a vaginal cultured cell line and on vaginal epithelial cells (VEC) donated by female volunteers. Antibody labeling was tested by western blotting, by light and electron microscopy, and by quantitative analysis of anti-ENT1 label on V19 multilayer cultures. Antibody specificity was tested by affinity adsorption.

Results: The ENT1 protein was present on VEC from human donors and on V19 cultured cells. The ENT1 antibody revealed protein bands at $50 \mathrm{kDa}$ and $30 \mathrm{kDa}$ on a western blot of $\mathrm{V} 19$ proteins. Light microscopy revealed only limited information on the sub-cellular location of the ENT1 protein, but immuno-electron microscopy showed the ENT1 protein predominantly located on the plasma membrane and lysosome-like structures. Label was also present over the endoplasmic reticulum (ER), Golgi complex, and cytoplasmic vesicles.

Conclusions: The results suggest a synthesis and degradation pathway for the ENT1 protein. However, the presence of ENT1 in junctional complexes and mitochondria suggest a more complex role for the protein. The ENT1 protein may potentially transport adenosine drug analogs such as tenofovir (TFV) and its prodrugs into and out of cells. The presence of ENT1 on VEC, with a rapid turnover, may have wideranging implications on anti-retroviral treatment (ART) therapies by removing them from their site of action. However, the bidirectional nature of ENT1 could mean that drugs such as TFV are also removed from cells. Transporter proteins such as ENT1 could shuttle the TFV through the vaginal epithelium to immune cells located in lower cell layers. Future studies will focus on determining if the ENT1 protein is active on vaginal cell plasma membranes, and if it has a role in the transport of nucleoside analogs.
\end{abstract}

Keywords: Tenofovir, Electron Microscopy, Retrovirus, Drug Delivery, Protein Expression, Transporter, Immunolabeling

\section{Introduction}

Development of prophylactic approaches for vaginal delivery of anti-retroviral treatment (ART) drugs has brought a focus on the normal physiology and health of the female vaginal tract. The use of ART agents, some of which are nucleotide analogs, has prompted an interest in endogenous membrane transporters of cells at sites where the drug is delivered, or where it will be active [1-4]. Expression of transporter proteins may influence drug disposition and retention in relevant sites of action, and thus have an effect on drug efficacy. Identifying an endogenous, transporter protein capable of providing a functionally active, naturally occurring target to access local and possibly systemic

( 2020 Webster et al; licensee Herbert Publications Ltd. This is an Open Access article distributed under the terms of Creative Commons Attribution License (http://creativecommons.org/licenses/by/3.0). This permits unrestricted use, distribution, and reproduction in any medium, provided the original work is properly cited. 
ART coverage would be desirable. Previous studies reporting the presence of a large number of membrane transporter proteins in the vaginal tract of human volunteers, observed varying expression levels of these proteins between the sampled subjects [1-3,5]. Differential expression of proteins was observed between the different sampling sites within the vaginal tract [2]. While the proteins were located associated with the cells in the specimens, there was no high-resolution information reported of protein expression at the cellular level.

In this study we focus on one specialized membrane transporter protein, called the equilibrative nucleoside transporter 1 (ENT1), a protein encoded by the SLC29A1 gene with a predicted molecular weight of $50.2 \mathrm{kDa}$ [6]. The protein is an equilibrative transporter, able to mediate influx (uptake) and efflux of nucleosides across membranes, with a high affinity for adenosine. The latter affinity is relevant because tenofovir (TFV) and its prodrugs, drugs administered vaginally in a number of products (e.g., intravaginal rings, vaginal films, gels, and fast-dissolving tablets [7-15]) aimed at preventing sexual HIV infection, is a nucleoside reverse transcriptase inhibitor analog of adenosine. The drug is delivered in the form of its pro-drug, fumarate salt, TFV disoproxil fumarate (TDF) that rapidly hydrolyzes to TFV in vivo. It is plausible that an active transporter protein could target extracellular drug, bringing it into cells and possibly taking it away from sites of useful activity. The aim of the study was to determine the feasibility of performing a high-resolution immunolocalization of the protein in vaginal epithelial cells using a commercial antibody.

Human ENTs are cell membrane nucleoside transporter proteins occurring as four isoforms (ENT1-ENT4) in almost all tissues throughout the body. These proteins play important roles in transporting nucleoside- and nucleotide-based small molecule drugs across membrane. ENT1 expression is critical for salvage of natural nucleotides and nucleosides for nucleic acid synthesis $[6,16]$, neurotransmission, and regulation of cardiovascular activity [17].

A commercial antibody was used to determine the presence of the protein on vaginal epithelial cells, either grown in cell culture, or isolated from female volunteers. The antibody was applied to proteins from cells and was also used for immunocytochemical approaches to determine if the subcellular location of the ENT1 protein could be elucidated. Vaginal epithelial cells from healthy female volunteers were compared with an immortalized vaginal epithelial cell line [18].

\section{Methods \\ Cells}

\section{V19 immortalized epithelial cell line}

Immortalized V19 vaginal epithelial cells [18] were cultured in a 1:1 mixture of keratinocyte serum-free medium (KSFM; Invitrogen, Carlsbad, CA, USA), and VEC-100 (MatTek Corp; Ashland, MA, USA) media at $37^{\circ} \mathrm{C}$ in a $5 \% \mathrm{CO}_{2}$ humidified incubator. The cells were maintained overnight under liquid media for confocal light microscopy (CLSM) immunolabeling studies. Air-interface multilayer cultures were prepared as previously described [19]. Suspensions of V19 cells in KSFM medium (Millipore Sigma) were added to the top chambers of Corning Transwell inserts (VWR, Inc, Radnor, PA), and sterile media added to the bottom chambers. Cells were cultured for 24-36 hr and the media from the top chamber removed to create an air-interface. Media in the bottom chambers was replaced every other day for up to 10 days.

\section{Epithelial Cells from female volunteers}

Ethical approval for involvement of women in this study was consented by the Aspire Institutional Review Board (project number OCIS-02A approved on 07/10/2017). Written informed consent was provided by all volunteers, and guidelines and policies established by the World Health Organization for good clinical practice (GCP) and Aspire IRB were followed. Female volunteers (aged between 20 and 53) were recruited to submit to a self-sampling protocol, where vaginal epithelial cells were collected using a menstrual soft cup [20]. Cells were removed from the soft cup by centrifugation, fixed in $4 \%$ formalin in $100 \mathrm{mM}$ phosphate buffer and stored at $4^{\circ} \mathrm{C}$ until used. Cells were collected from Caucasian females in their 20's (IDs 041 \& 011), 30's (IDs 008, 019 \& 037), and 50's (ID 051).

\section{Western blotting}

V19 cells were lysed with REPA buffer, standard recommended protocol $(89900$, ThermoFisher, Carlsbad, CA) and processed for SDS-PAGE according to the manufacturers recommended conditions for western blot analysis. A lysate of MDA-MB-435s cells, known to express ENT1 [21] were used as a positive control. Primary antibody (LS-B3385, LSBio, Inc., Seattle, WA) was used at 1:1000 dilutions and the secondary antibody (LiCOR IRDye 680 Donkey anti-Rabbit IgG, LiCOR) was diluted at $0.2 \mathrm{ug} / \mathrm{ml}$. Blocking buffer with $0.1 \%$ BSA in Tris-buffered saline containing $0.1 \%$ Tween 20 (TBS-T) was used at room temperature with gentle agitation for $1 \mathrm{hr}$ and TBS-T buffer was used for washing.

\section{Microscopy \\ Chemical fixation}

Cells for light or electron microscopy were chemically crosslinked by immersion in $4 \%$ formalin in $100 \mathrm{mM}$ phosphate buffer. Cells were stored in the fixative until used.

\section{Light microscopy}

Fixed cells were prepared for immunolabeling using established methods. For labeling, the cells were embedded in $2 \%$ low melting point agarose, washed with phosphate buffered saline (PBS) and then with PBS containing $0.15 \%$ glycine. The cells were permeabilized by $0.1 \%$ Triton X-100 in PBS for 10 min, treated with $1 \%$ bovine serum albumin (BSA) in PBS, and incubated in anti-ENT1 antibodies diluted in PBS-BSA (LS-A9777 and LA-B3385; LSBio Inc., Seattle, WA), washed and incubated in fluorescently-labeled secondary antibodies 
(Jackson ImmunoResearch; West Grove, PA). All cells were visualized by staining with DAPI (4,6-Diamidine-2'-phenylindole dihydrochloride; Millipore Sigma) and fluorescent concanavalin A (Vector Laboratories). The immunolabeled cells in agarose were mounted on glass slides in Moviol containing DABCO (1,4-diazabicyclo[2.2. 2]octane; Millipore Sigma), and imaged by CLSM (LSM 510 Meta; Carl Zeiss Inc., Thornwood, NY).

\section{Electron Microscopy}

Formaldehyde-fixed cells were washed to remove aldehyde and then embedded as a pellet in $2 \%$ or $12 \%$ gelatin. Pellets were cut into small cubes, soaked in $2.3 \mathrm{M}$ sucrose overnight, and frozen on metal pins in liquid nitrogen. The specimens were dehydrated while still frozen by immersion in methanol maintained at $-95^{\circ} \mathrm{C}$ (AFS2 Leica Microsystems), which was gradually warmed to $-50^{\circ} \mathrm{C}$ while gradually replacing the methanol with unpolymerized Lowicryl HM20 resin. Resininfiltrated specimen blocks were polymerized under UV light at $-50^{\circ} \mathrm{C}$. Sections were labeled with specific antibodies and protein A-gold (University of Utrecht, The Netherlands).

\section{Quantification}

V19 epithelial cells grown on Corning Transwell inserts (VWR, Inc, Radnor, PA) were fixed in 4\% formaldehyde, soaked overnight in $2.3 \mathrm{M}$ sucrose, frozen in liquid nitrogen and dehydrated by freeze substitution in cold methanol [22]. Sections were labeled sequentially with rabbit anti-ENT1 and protein A-gold. Gold particles bound to sections were counted and correlated with profile areas or profile lengths of identifiable sub-cellular structures using established methods $[23,24]$. Counting and application of overlay grids was performed using STEPanizer software [25] to obtain estimates of gold particle densities on area profiles of subcellular organelles, and on length profiles of plasma membrane and junctional complexes. The sections through the cells on Transwell inserts were cut from filter base to apical surface, so were treated as vertical sections [26]. Sampling was performed using cycloid test line overlays [24]. Counting data was further processed using Excel spreadsheets (Microsoft).

\section{Results}

\section{Cell lines}

Cultured V19 vaginal epithelial cells, when labeled with an antibody to the equilibrative nucleoside transporter 1 peptide antibody (anti-ENT1), show labeling over the whole cell (Figure 1A). The label was punctate and was spread through the whole cell. Regions identified as being cell periphery (Figure 1A) by phalloidin labeling (Figure 1B) showed increased amounts of antibody label. Reduced levels of labeling were observed in regions occupied by nuclei, as visualized by DAPI (Figure 1C). An overlay image of the three labeling patterns (anti-ENT1, phalloidin, and DAPI) showed the distribution of the anti-ENT1 antibody over the cell cytoplasm (Figure 1D), with less label over regions occupied by nuclei. Cell periphery was demon-

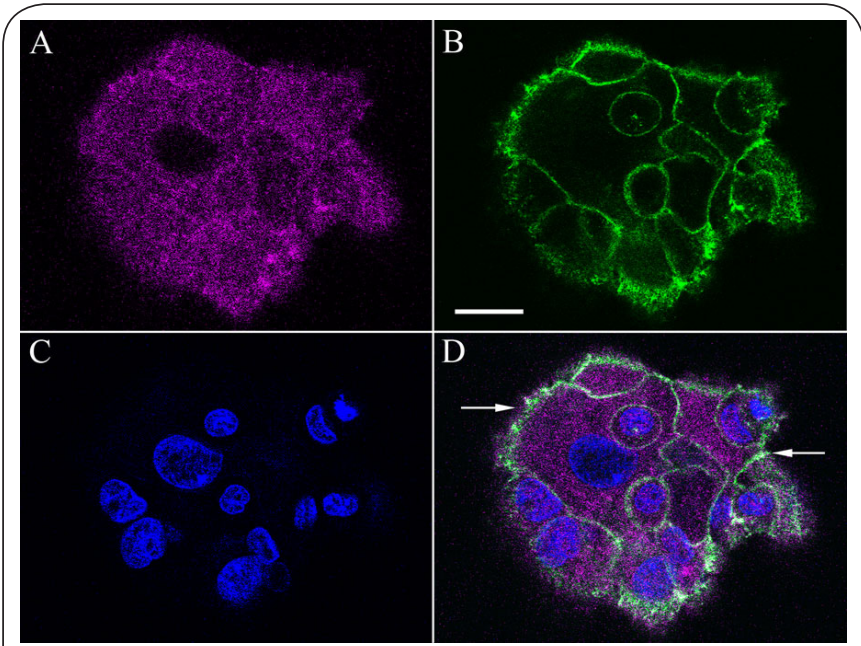

Figure 1. Anti-ENT1 antibody label on V19 vaginal epithelial cells.

(A) Fluorescent signal is distributed throughout the cells. Some regions have high levels of labeling than others. (B) Phalloidin labeling of the same cells. The fluorescent phalloidin binds to actin in the cells. The signal is located around the cell periphery and on focal adhesion points. (C) DAPI labeling, binding to the nucleic acids of the cell nuclei.

(D) A composite overlay image of the three labels. Phalloidin (actin) labeling around the cells (arrow) has been bleached out by the anti-ENT1 signal, which suggests there is specific antiENT1 labeling around the cell periphery. Scale Bar $=20 \mu \mathrm{m}$.

strated on the overlay image (Figure 1D), where the anti-ENT1 labeling bleached out the phalloidin label. A western blot of V19 vaginal cell lysates probed with anti-ENT1 showed binding to two bands in the $50 \mathrm{kDa}$ and $30 \mathrm{kDa}$ regions of the blot (Figure 2).

In a separate labeling experiment, V19 cells were exposed to ENT1 peptide already pre-incubated with the anti-ENT1 antibody. Images were collected by CLSM using settings adjusted to optimally image antibody labeling in the absence of ENT1 peptide inhibition (Figure 3A), and the same settings used to image cells labeled with the anti-ENT1antibodies adsorbed to ENT1 peptide. The anti-ENT1 antibodies labeled cells in a punctate pattern (Figures 3 A and 3B). Signal was concentrated over regions corresponding to cell periphery, and reduced in regions occupied by cell nuclei (Figures $\mathbf{3 A}$ and $\mathbf{3 B}$ ).

Adsorbing the anti-ENT1 antibody to the ENT1 peptide reduced the labeling over the V19 cells (Figures 3C and 3D). The signal was not completely obliterated, but signal over the cell cytoplasm was reduced sufficiently to make cell periphery labeling more noticeable (Figures $3 \mathrm{C}$ and $3 \mathrm{D}$ ). The cell periphery and nuclei were imaged using phalloidin and DAPI respectively. However, for clarity of presenting the specific anti-ENT1antibody labeling, these signal data are not shown.

\section{Human cells}

The anti-ENT1 antibody was applied to vaginal samples col- 


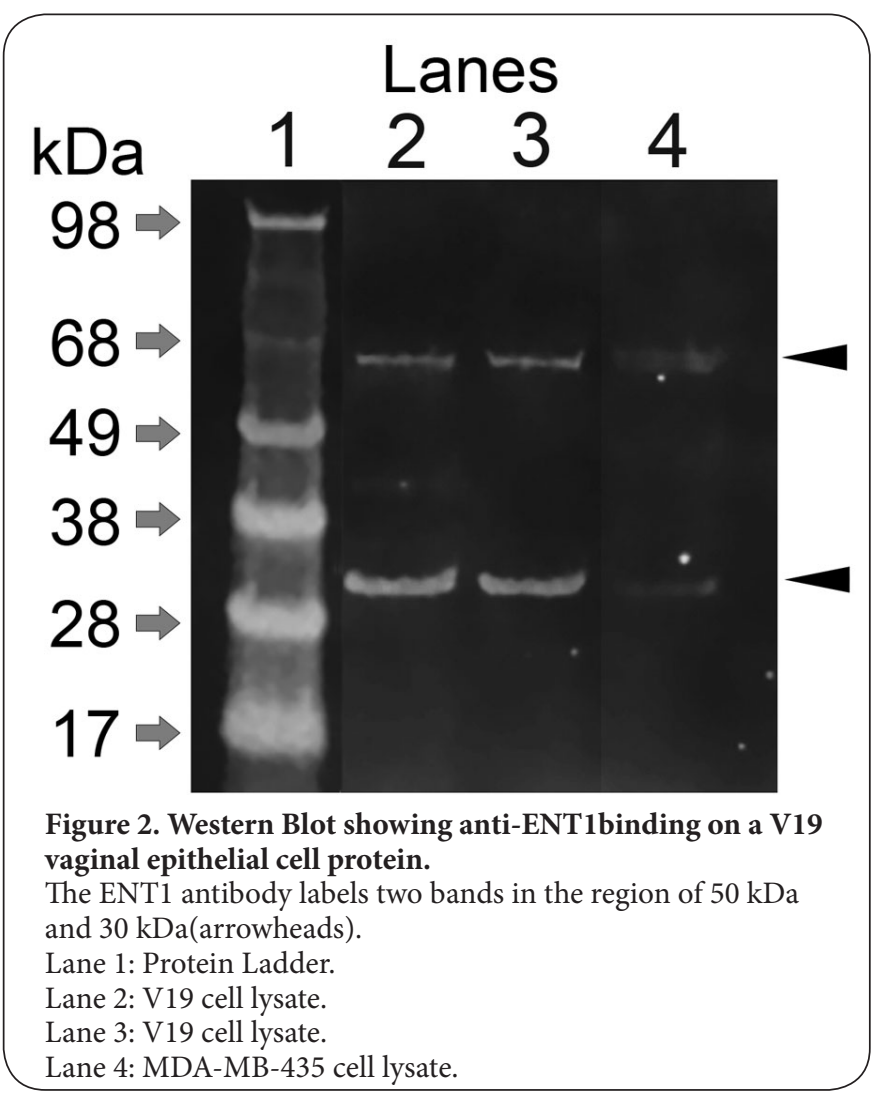

lected from three different female volunteers and the specific signal was recorded (Figure 4). The cells, collected from volunteers 019 on visit 1, 041 on visits 2 and 6, and 008 on visit 4 , were labeled with anti-ENT1 antibodies and fluorescent secondary antibodies. Cells were then labeled with DAPI to identify the cell nuclei. Anti-ENT1 labeling was similar to that observed in the cultured V19 vaginal epithelial cells. Signal was detected around the cell periphery (Figure 4A) and over the cell cytoplasm (Figures 4B and 4C). Regional concentrations of antibody were observed within cells (Figure 4B) and around the cell periphery (Figure $\mathbf{4 C}$ ). Cells from the same volunteer, but collected at a later time, showed a different labeling pattern (Figure 4C) than observed over cells collected in the earlier visit (Figure 4B). Cells collected during the later visit showed more concentrated labeling around the cell periphery and less intracellular label (Figure 4D).

Vaginal epithelial cells were collected from three different female volunteers during multiple visits, and were labeled with the anti-ENT1 antibody in one experiment. All the cells were processed synchronously with the same reagents, and imaging was performed on the same day using identical settings on the microscope, thus making it possible to directly compare results. Cells from volunteer $051 \mathrm{~A}$ (second visit) labeled with the ENT1 antibodies (Figures 5A-5D) but cells from volunteer $011 \mathrm{~F}$ (visit seven: Figures 5E-5H) and 037B (visit three: Figures 5I-5L) did not label with the ENT1 antibody. A small amount

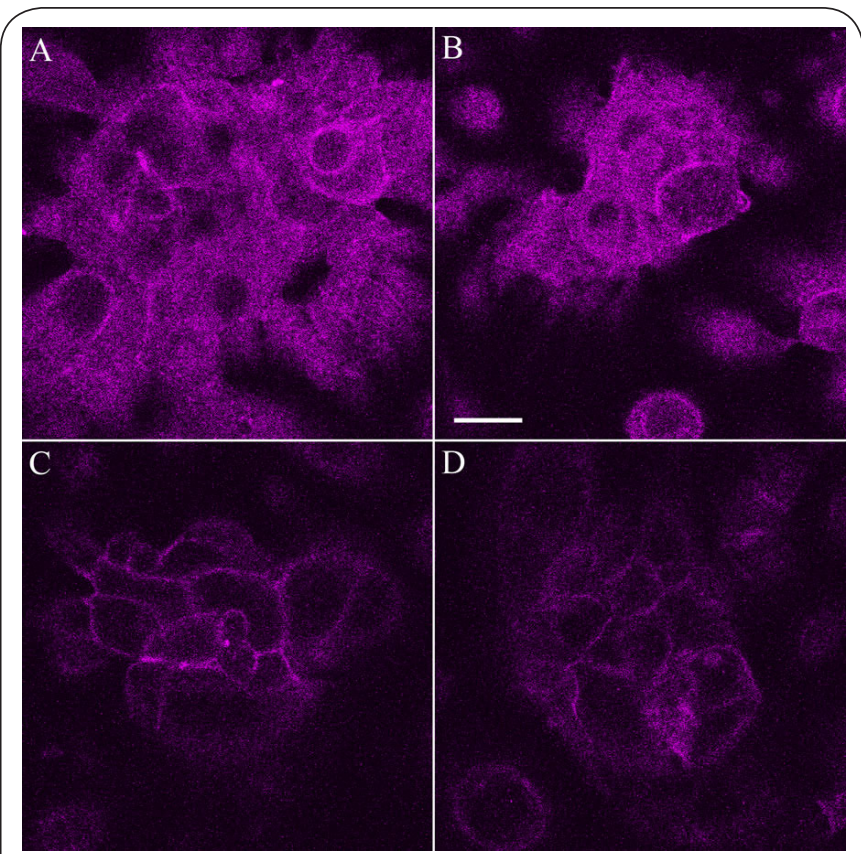

Figure 3. Effect of ENT1 peptide inhibition on anti-ENT1 binding to V19 vaginal epithelial cells. Panels A \& B) V19 vaginal epithelial cells labeled with antiENT1 antibodies. Signal is observed throughout the cells, and appears to also be located around the cell periphery. Panels C \& D) V19 vaginal epithelial cells labeled with antiENT1 antibodies, which had been first incubated with ENT1 peptide. Specific signal on the cells has been reduced. Labeling of the cell periphery is more pronounced. Scale Bar $=20 \mu \mathrm{m}$.

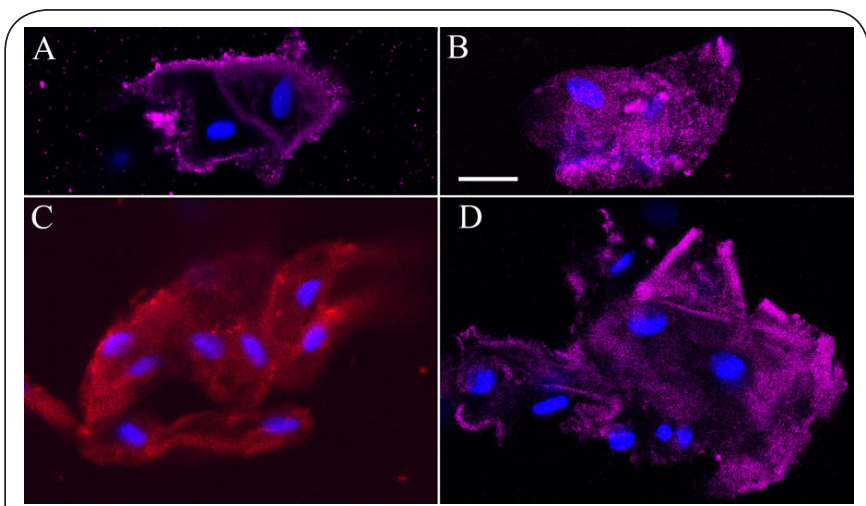

Figure 4. Human epithelial cells labeled with anti-ENT1 antibodies.

The anti-ENT1 antibody labeling on vaginal epithelial cells collected from human volunteers. A) Female 019 visit 1 , B) Female 041A visit 2, C) Female 041E visit 6, D) Female $008 \mathrm{C}$ visit 4 . The antibody label, in purple (A, B \&D) or red (C), is located around and inside cells. Concentrated regions of label are present at intracellular sites. Scale Bar $=20 \mu \mathrm{m}$.

of label was observed over the nuclei of some cells from volunteer $011 \mathrm{~F}$ (Figure 5G). Cells were visualized by treating with concavalin A to detect the cell outline, and with DAPI to label the cell nuclei. 


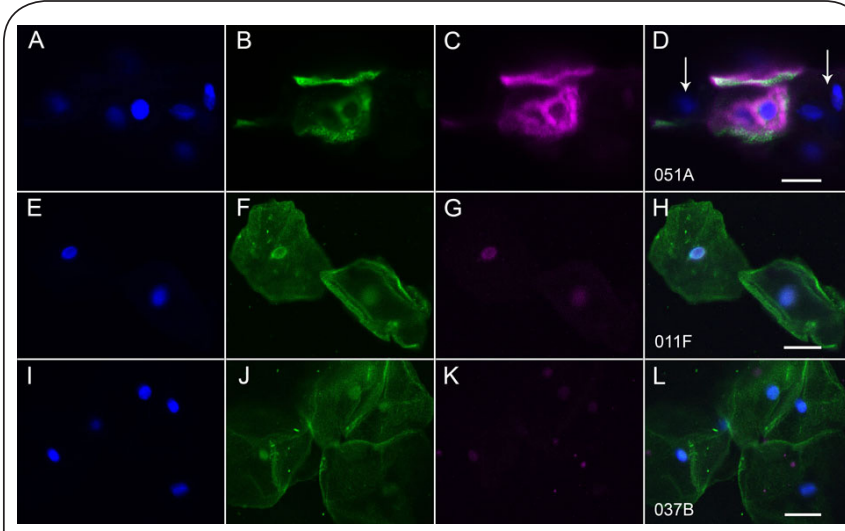

Figure 5. Human epithelial cells labeled with anti-ENT1 antibodies.

Cells from female volunteers were labeled together using the same anti-ENT1 antibody preparation and other reagents. The antibody labeling was observed on cells from one volunteer (051A: Panels A-D) with specific label associating with cell cytoplasm. Some cells in the preparation did not label with the ENT1 antibody (arrows). Cells from two other volunteers (011F and 037B: Panels E-H \& I-L) did not label with the antiENT1 antibodies. The ENT1 antibodies were visualized with secondary antibodies (purple). DAPI (blue) and concanavalin A (green) were used to contrast the cells. Scale Bars $=20 \mu \mathrm{m}$.

\section{TEM of Cell Cultures}

Cultured V19 cells were prepared for cryosectioning and the thawed cryosections were labeled with anti-ENT1 antibodies and protein A-gold. The antibodies labeled the thawed cryosections in a similar way to the labeling observed on the sections through the Lowicryl-embedded cells. Low amounts of label were observed over vesicle profiles (Figure 6A), lysosome-like structures (Figure 6B), over ER-like structures (Figure 6C), and on the plasma membrane (Figure 6D). Anti-ENT1 antibody label associated with the cell cytoplasm and with cytokeratin bundles (data not shown). Golgi complexes were not detected in the cryosectioned material.

\section{LabelingV19 cells on Transwell inserts}

The V19 cells cultured on Transwell filters, with an air interface at the apical surface, labeled with the anti-ENT1 antibodies (Figure 7). Examination by CLSM showed patchy antibody labeling over the cells, with some regions of the multilayer cell structures labeling, while other regions did not label (Figures 7A and 7B). The phalloidin label was associated with small areas of the multi-cell layer, and often the phalloidin label was present in regions where there was no anti-ENT1 labeling (Figure 7B). The anti-ENT1 label was punctate over the cells, with reduced labeling in regions where nuclei were present (Figure 7B). The signal was sometimes more concentrated, suggesting an accumulation in perinuclear regions (Figure 7B).

Immuno-EM labeling of the multicell layers on Transwell inserts detected protein A-gold particles over many cellular structures. The gold particles, indicating anti-ENT1labeling,

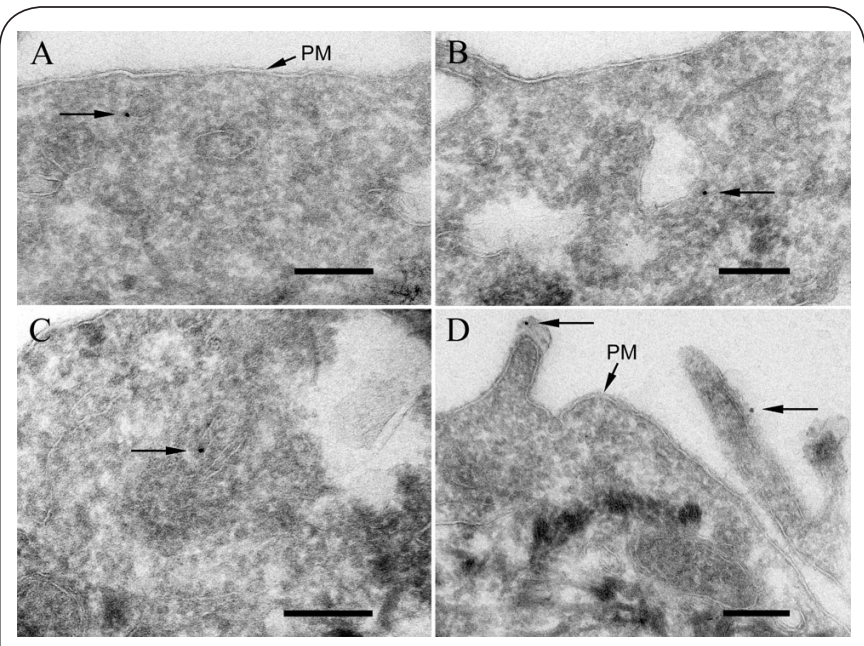

Figure 6. Anti-ENT1 labeling on thawed cryosections of V19 cells.

Electron micrographs of thawed cryosections through V-19 vaginal epithelial cells were labeled with anti-ENT1 antibodies and $10 \mathrm{~nm}$ protein A gold. Protein A-gold labeling was present at low density but was always associated with intracellular structures. A) A small vesicle profile close to the cell surface has a gold particle attached arrow. The plasma membrane (PM) identifies the cell surface. B) An endosomeor lysosome-like profile close to the plasma membrane (PM), or cell surface, is labeled. C) Endoplasmic reticulum-like profile is labeled with a gold particle (arrow). D) Gold particles (arrows) on the plasma membrane (PM) of microvilli indicate ENT1 antibody binding. Scale Bars $=200 \mathrm{~nm}$.
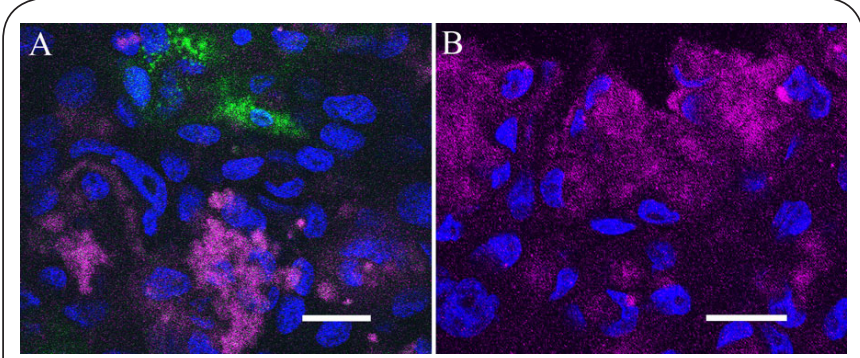

Figure 7. Anti-ENT1 labeling on cells growing on Transwell inserts.

Light micrographs (CLSM) images of V19 human vaginal epithelial cells grown as a multi-layer sheet on Transwell filter membranes and labeled with anti-ENT1 antibodies. The antibody labeled non-defined regions on the multilayer sheet of cells. A) The antibody labeled regions around the cell nuclei (DAPI, in blue), but seldom over the nuclear region. Phalloidin label was not extensive throughout the cell layers, and was restricted to regions where there were lower amounts of anti-ENT1 label. B) The anti-ENT1 label was associated with cells and had a punctate appearance. The label was around the cell nuclei but seldom over the nuclear region. In some instances the antibody label was concentrated over perinuclear spots. Phalloidin labeling is green and DAPI (nucleic acids) is blue. Scale Bars $=20 \mu \mathrm{m}$.

were observed over endoplasmic reticulum profiles in the V19 cells (Figure 8A), on the nuclear envelope and cell cytoplasm 
(Figure $8 \mathrm{C}$ ). Gold particles also bound to the lumen (Figure 8B) and sides (Figure 8D) of junctional complexes, which were present where adjacent cells were joined.

Protein A-gold binding, indicating the presence of antiENT1 labeling, on mitochondrial inner membranes (Figure 8E), mitochondrial outer membranes (Figure 8F), and with other double-membrane-bounded profiles (Figure 8F). Very occasionally, small vesicle profiles were observed to have protein A-gold bound to them (Figure $\mathbf{8 G}$ ). The large number of gold particles associated with the small vesicle profiles suggested a concentration of protein within the structure. Other subcellular structures that labeled with the anti-ENT1antibodies included lysosome-like profiles (Figure 9A), Golgi-like profiles (Figure 9B), and cytoplasmic bundles of cytokeratin (Figure 9C).

\section{Quantifcation}

The specificity of label observed over sections of multi-lay-

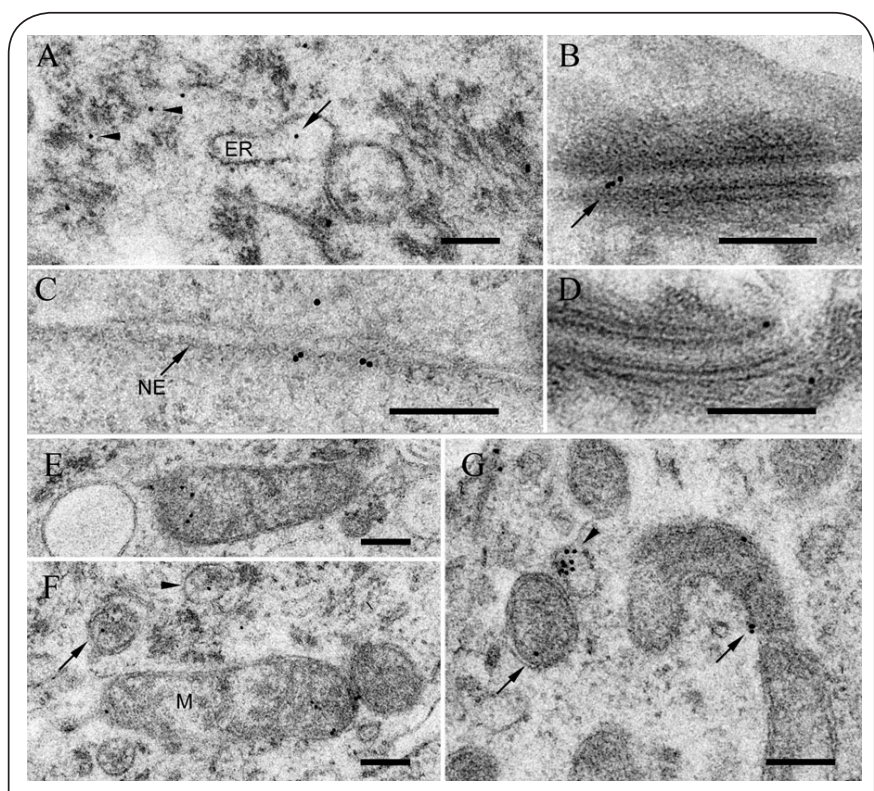

Figure 8. Anti-ENT1 labeling on cells growing on Transwell inserts.

Electron micrographs of sections through Lowicryl HM20embedded V-19 cells labeled with anti-ENT1 antibodies and $10 \mathrm{~nm}$ protein A gold. A) Gold particles arrow were associated with endoplasmic reticulum(ER) profiles and cytokeratin-like structures(arrowheads). B) Gold particles(arrow) bound to the inner part of a junctional complex between two cells. C) The nuclear envelope(NE) labels with protein A gold. D) Gold particles associate with different regions of the junctional complex. E) Gold particles are present over mitochondria and small vesicular structures. F) Gold particles are bound to a region over the inside of a mitochondrion. In addition to labeling the inside of a mitochondrion, there are gold particles on the mitochondrial membrane (M), over other double-membrane structures (arrow), and single membrane structures (arrowhead). The double membranes around the intracellular bodies suggest they are mitochondria. G) Gold particles label mitochondria (arrows) and a small singlemembrane vesicle profile(arrowhead). Scale Bars $=200 \mathrm{~nm}$. ered V19 cells grown on Transwell inserts prompted a more detailed analysis using stereological methods to correlate the gold labeling with identifiable sub-cellular structures. Quantitatively, most of the gold particle label was observed over the lysosome lumen and plasma membrane (Figures 10A and 10B). Gold particles also associated with the cytoplasm, endoplasmic reticulum (ER), vesicle profiles and junctional complexes (Figures 10A and 10B).

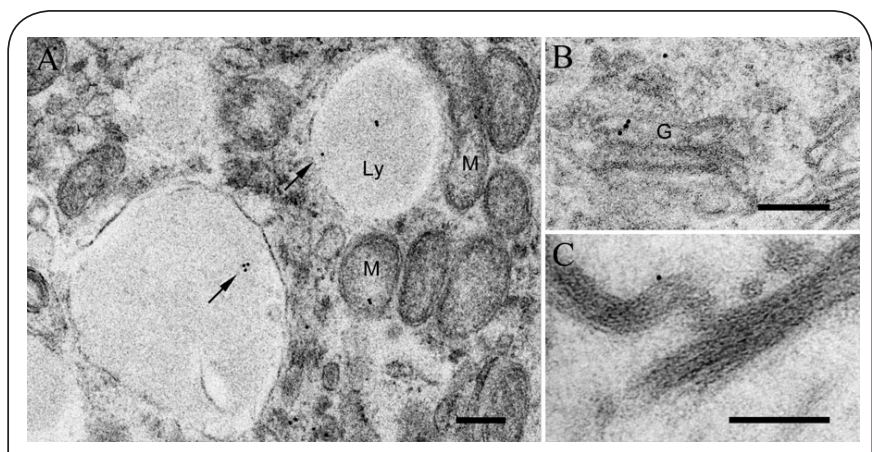

Figure 9. Anti-ENT1 labeling on cells growing on Transwell inserts.

Electron micrographs of sections through Lowicryl HM20embedded V-19 cells labeled with anti-ENT1 antibodies and $10 \mathrm{~nm}$ protein A gold. A) Lysosome-like profiles (Ly) label with the anti-ENT1 antibodies, with the gold particles (arrow) associating with the lysosome lumen. Mitochondrial profiles (M) are also labeled. (B) A Golgi-like profile (G) is labeled with gold particles. C) Cytoplasmic cytokeratin-like fibers label with the antibody. Scale Bars $=200 \mathrm{~nm}$.

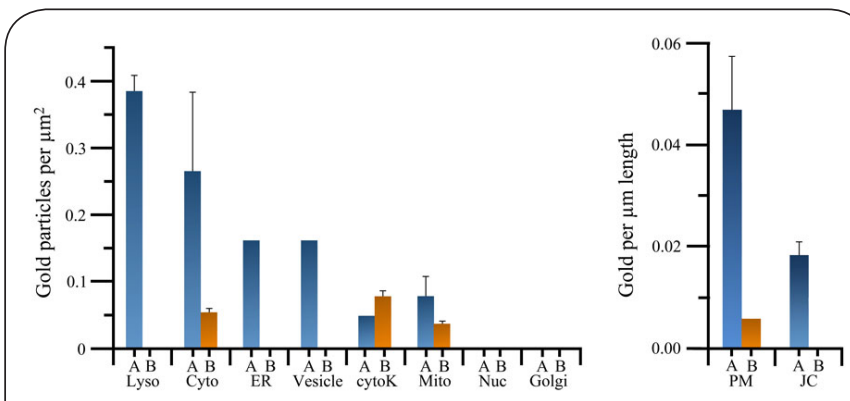

Figure 10. Quantification of gold label on cells grown on Transwell inserts.

Results of quantifying the anti-ENT1 antibody and protein A gold label on Lowicryl HM20-embedded V19 vaginal epithelial cells. Column A (blue) antibody label; Column B (orange) antibody label after affinity adsorption. A) The predominant labeling was detected over lysosome (Ly) profiles, the cytoplasm (Cy), and mitochondria (Mi). Incubating the anti-ENT1 antibody with ENT1 peptide before labeling the sections, specific label over lysosome (Ly) and mitochondrial (Mi) profiles was completely inhibited. ENT-1 peptide adsorption reduced, but did not completely inhibit, the labeling over the cytoplasm. B). Counts of gold particles associating with membrane profiles showed the label to be mostly associated with the plasma membrane (PM) and junctional complexes (JC) between cells. Peptide inhibition with ENT1 reduced the label on the plasma membrane (PM) and completely inhibited binding on the junctional complexes (JC). 
Incubating the anti-ENT1 antibody with the ENT inhibiting peptide completely abolished labeling over lysosomes, ER, vesicle profiles, and junctional complexes (Figures 10A and 10B). Labeling was partially abolished over the cell cytoplasm and the plasma membrane (Figures 10A and 10B). Gold particles, indicating anti-ENT1 antibody labeling, were also detected over cytokeratin bundles within the V19 cells and mitochondria. However, peptide adsorption of the ENT1 antibody did not inhibit cytokeratin labeling, and only partially blocked mitochondrial labeling (Figure 10A).

\section{Discussion}

Understanding vaginal physiology is important, especially in the context of studying and preventing sexually transmitted infections. The vaginal epithelial layer (mucosa) has unique properties able to protect against infection yet maintain a healthy microbiome. When using drug delivery systems such as intravaginal rings for ART it is important to consider the normal physiology of vaginal epithelial cells and how the cells might interact with the rings and the drugs they deliver. For example, cells in the vaginal tract are known to express drug transporters [1,2], proteins that move drugs into an out of cells [2]. The location and expression levels of drug transporters may influence the efficacy of drugs as they interact with these transporter proteins. Specific interactions between the drug transporters present on cells and the drugs being used for prophylaxis may alter the pharmacokinetics of the regimen. Of particular interest for studies where nucleoside reverse transcriptase inhibitors are used for ART, is the equilibrative nucleoside transporter 1 (ENT1), a member of the equilibrative solute carrier family of drug transporters. The gene encodes a transmembrane glycoprotein able to mediate the cellular uptake of nucleosides and antiviral drugs $[\mathbf{2 7}, \mathbf{2 8}]$. HIV preexposure prophylaxis (PrEP) strategies largely use TDF, a pro-drug of TFV, a nucleoside reverse transcriptase inhibitor analog of adenosine. It is possible that ENT1 protein, with a high affinity for adenosine, may also have an affinity for TFV and TDF.

In this study we used immunocytochemistry to detect ENT1 protein expression by vaginal epithelial cells. Using the anti-ENT1 antibody to label whole cells for light microscopy examination, and to thin sections for examination by electron microscopy, we could demonstrate the presence of the ENT1 protein within vaginal epithelial cells and alsolocate the protein within the cells. The ENT1 antibody label associated with the plasma membrane, cytoplasm, lysosome-like structures, junctional complexes where cells had joined, endoplasmic reticulum and cytoplasmic vesicles. Some labeling over mitochondria was present, but labeling over cytokeratin bundles within vaginal epithelial cells appeared to be non-specific. No label was detected over the cell nucleus or over the Golgi complex when a quantitative analysis was performed. However, membrane profiles recognizable as Golgi complex had gold particles associated with them. The labeled Golgi structures were small and in low enough number to be overlooked by the quantitative analysis sampling. Vaginal epithelial cells undergo a gradual loss of intracellular organelles as they keratinize [29] so low numbers of intracellular organelles were expected.

Although vaginal epithelial cells gradually lose their intracellular organelles, DNA and RNA, there were enough structures present in the V19 cultured cells to obtain an overview of where the ENT1 protein was expressed. The plasma membrane, cytoplasm, and lysosomes were the main location of the ENT1 protein. Together with Golgi, ER and vesicle locations a synthesis and degradation pathway is suggested, where the ENT1 protein is formed in the Golgi complex, transported to the ER and then to the plasma membrane. Recycling of ENT1 protein from the plasma membrane to lysosomes may then occur. Subcellular locations that undermine this simplistic synthesis and degradation model are the presence of ENT1 in junctional complexes between cells, and over mitochondrial membranes. The presence of ENT1 in junctional complexes and mitochondria suggest a more complex role for the transport proteins within the vaginal epithelial cells.

The ability to detect proteins using immunocyochemistry is dependent on a variety of factors, which can influence the quality of results. A well-characterized antibody with a known specificity is as important as an accurate interpretation of the data collected. The antibody binding must have high antigen specificity, a property highlighted by studies documenting the low quality of some commercial antibodies [30-33]. Reports critical of commercial antibodies have resulted in calls for more stringent application of immunocytochemistry [34-36], a call whole heartedly supported by this team. In the current study, we used a commercial antibody raised against a synthetic 16 amino acid peptide from internal region of human ENT1, the only previous validation of which was immunolabeling of formalin-fixed, paraffin-embedded human brain tissue by the supplier. This validation confirmed that the anti-ENT1 antibody labeled a sub-set of cells in human brain sections.

Further validation of the antibody was carried out during our immunocytochemical evaluation of anti-ENT1 binding on vaginal epithelial cells. We first tested the antibody on V19 vaginal epithelial cells grown in culture, examining the cells by light microscopy. Using fluorescent secondary antibodies to visualize the anti-ENT1 antibody binding, we showed labeling patterns on cultured V19 cells that were difficult to interpret. The cell cytoplasm had punctate labeling which did not conform to patterns of easily recognizable structures. However, when the cells were co-labeled with phalloidin, an actin-binding protein, labeling around the cell periphery became obvious. Superimposition of the anti-actin and anti-ENT1 protein labeling caused a bleaching effect of both fluorescent dyes suggesting they were co-localized.

Confirmation that the antibody was mono-specific was obtained by western blotting. The antibodies recognized two protein bands on a western blot of V19 cell proteins. The upper band, around $50 \mathrm{kDa}$ corresponds with the previously 
reported predicted molecular weight of $50.2 \mathrm{kDa}$ [6]. It is not yet clear what the protein band recognized in the $30 \mathrm{kDa}$ region is, but this is under study. The ability of the antibodies to bind specific epitopes independent of binding to tissues or cells is considered to be critical in establishing specificity [34].

We performed an affinity adsorption test, where diluted antibody was mixed with specific antigen before being used to label cells or sections, to determine the specificity of the antibodies to the commercial ENT1 peptide. By light microscopy, the adsorbing peptide antigen did remove some signal. However, some signal remained and was concentrated around the cell periphery, confusing the observation that the ENT1 antibody was labeling the cell membrane. The adsorption control is considered to be a weak control for making conclusions on specificity [34] because it is only able to confirm the antibody is able to bind to the peptide antigen it was prepared against. However, some specific signal on the V19 cells was removed. Affinity adsorption of the ENT1 antibody was more successful when adsorbed antibodies were applied to thin sections for electron microscopy. When applied to thin sections all of the ENT1 labeling was blocked from binding the plasma membrane, structures identified as lysosomes, and other intracellular organelles.

In order to obtain more data, the anti-ENT1 antibody was applied to multi-layer cultures of V19 cells grown on Transwell filters. For the multi-layered epithelium to form, the cells are grown for up to 10 days at an air-liquid interface. At the light microscopic level, the labeling was again inconclusive. We were able to determine that the tight binding of cells to one another was restricting antigen access in the multi-cell layer and limiting the amount of cellular permeabilization. Attempts to increase antibody accessibility to the multi-cell layers resulted in the cell layers falling away from the filter substrate during the labeling protocols. Attempts to prepare semi-thin sections for immunolabeling at the light microscope level were attempted. However, the membrane filter supporting the multi-cell layers made it difficult to obtain flat sections with no disruption of the cell layers.

Labeling densities on thin sections for electron microscopy were low. However, the low density was present over thawed cryosectioned cells as well as cells embedded in resin. There appeared to be no difference in labeling sensitivity between the cryosections and resin sections. This was useful to discover because of the difficulty in cryosectioning cells grown on Transwell inserts. Although the Transwell insets are marketed as being useful for microscopy, obtaining cryosections through them, and obtaining sequential sections, is technically difficult. The resin sections labeled with the ENT1 antibody but the amount of labeling was low. However, a clear pattern of labeling was evident from qualitative observation. Structures observed to label were consistently labeled, and the labeling pattern was supported by the data obtained using quantification of gold particles.

Anomalous labeling of a $30 \mathrm{kDa}$ band observed by western blotting, and the presence of ENT1 labeling over junctional complexes and mitochondrial membranes may indicate an unidentified cross-reactivity, a well-documented limitation of immunolabeling experiments [35]. Antibodies against a defined antigen, either a whole protein or a peptide, can sometimes exhibit specific binding to an unrelated protein. The antibody will bind to structurally related antigens, with a different amino acid sequence. Examples of this crossreactivity of antibodies are described elsewhere [35]. While we have no evidence that the ENT1 antibody is binding to an unrelated protein, the possibility must be considered as studies on ENT1 labeling of VEC move forward.

The V19 cell line was established from vaginal biopsies [18] in order to create an artificial vaginal system to enable laboratory testing $[19,37,38]$. The cell line is a well-characterized vaginal epithelial system, yet, although the cells have a vaginal tract origin, they are not freshly collected from volunteers. Access to freshly collected vaginal epithelial cells was therefore important for supporting the data collected from immunolabeling of V19 epithelial cell cultures. Epithelial cells collected from volunteers showed the ENT1 antibody labeled the plasma membrane of cells as well as intracellular structures, thus supporting the data obtained from cell culture. The labeling patterns were variable between volunteers with some cells showing a clearly defined plasma membrane label while cells from other volunteers showed diffuse labeling throughout the cell cytoplasm.

Labeling the epithelial cells collected from multiple volunteers revealed heterogeneous expression of the ENT1 proteins. While most cells from volunteers labeled with the anti-ENT1 antibody, two volunteers provided cells that did not label with the antibody. The different labeling of the vaginal epithelial cells did not correlate with any differences between the volunteers as all were in the same age range and from the same ethnic background. All were white and spanned an age range between their 20's 30's and 50's. Of the two volunteers in their 20's, one provided ENT1-positive cells (ID: 041) on two separate visits, while the other volunteer had ENT1-negative cells (ID: 011). Three volunteers were in their 30 's and while two had ENT1-positive VEC (ID: 008, 019) the third had ENT1-negative cells (037). The volunteer in her 50's provided ENT1-positive cells.

Interestingly, the inability of the ENT1 antibody to label some VEC provides an important confirmation of antibody specificity in the form of a negative control. Usually the negative control used to confirm antibody specificity is a cell line or tissue that is known to not express the target protein $[34,35]$. For our study, we were able to use vaginal epithelial cells from female volunteers. Cells collected from some volunteers showed negative labeling under the same labeling conditions as applied to cells from other volunteers, which were positive for ENT1 labeling.

\section{Conclusions}

In this study we have shown preliminary results to suggest 
that the ENT1 protein is functionally expressed by vaginal epithelial cells from human volunteers and by vaginal epithelial cells in culture. We have labeled cells with the ENT1 antibody and have shown the specific label, removed by adsorbing the antibody to the inhibiting peptide, was not distinctly labeling identifiable cell structures by CLSM. We have used the ENT1 antibody to identify two protein bands by western blotting, and have shown that the ENT antibody does not bind to all vaginal epithelial cells. High-resolution imaging using the ENT1 antibody on thin sections of cultured V19 cells showed a low labeling density on thawed cryosections and on Lowicryl resin-embedded sections, by TEM. High-resolution imaging of thin sections labeled with anti-ENT1 and colloidal gold particles identified anti-ENT1 labeling over easily identifiable intracellular structures. The specific labeling on thin sections was confirmed by quantifying the labeling patterns. This study illustrates how the combined approaches of light and electron microscopy can reveal antibody-binding specificity of a commercial antibody to vaginal epithelial cells.

The use of antibodies to locate antigens within cells and tissues is a powerful approach for understanding how cells work. Identifying the cells expressing the protein, and knowing where the antigen is located within the cells offers information on how the cells and the antigen might function. For example, if the protein is located at an intracellular site within cells, its activity might not be important for transporting molecules across outer cell membranes. If, however, a transporter protein is present on the plasma membrane, and is active at this site, depending on the mode of action of the protein, it may have the ability to take drugs into the cells from an extracellular location. Cell shedding, a normal process of the vaginal epithelium where the top layer of cells become detached from the epithelium and are washed away, may result in intracellular drug also be removed.

The presence of a drug transporter on cells within the vaginal tract, with the potential ability to collect adenosine drug analogs such as TFV, suggests a need for further study. For example, the ENT1 protein may be upregulated in the presence of TDF/TFV, and cells expressing the transporter may be able to accumulate ART drugs. Considering the high turnover of epithelial cells in the vaginal tract of approximately one cell layer very 4 hours $[29,39]$, it is possible that drugs could be removed from their site of action if they are absorbed into cells being shed from the epithelial cell layer, and thus losing some of its efficacy. However, the bidirectional nature of ENTs could mean that drugs such as TFV are also removed from cells, along with adenine if ENT1 is over-expressed. Interaction of ART drugs with the vaginal epithelial cells may influence delivery to immune cells in the vaginal epithelium, as these are the target cells for HIV. It has been estimated that the vaginal epithelium is typically 28 cell layers thick [40] Transporter proteins such as ENT1 could shuttle the TFV through the vaginal epithelium to immune cells located in the lower cell layers.

\section{List of Abbreviations}

ART: anti-retroviral therapy

BSA: bovine serum albumin

CLSM: confocal laser scanning microscope

DABCO: 1,4-diazabicyclo[2.2. 2]octane

ENT1: equilibrative nucleoside transporter 1

ER: endoplasmic reticulum

KSFM medium: Keratinocyte Serum-Free Growth Medium

PBS: phosphate buffered saline

PrEP: HIV preexposure prophylaxis

TDF: tenofovir disoproxil fumarate

TEM: transmission electron microscope

TFV: tenofovir

VEC: vaginal epithelial cells

\section{Competing interests}

The authors declare that they have no competing interests.

Authors' contributions

\begin{tabular}{|l|c|c|c|c|c|c|}
\hline Authors' contributions & PW & JC & SW & MG & RBP & MMB \\
\hline Research concept and design & $\checkmark$ & -- & -- & -- & -- & $\checkmark$ \\
\hline Collection and/or assembly of data & $\checkmark$ & $\checkmark$ & $\checkmark$ & $\checkmark$ & $\checkmark$ & -- \\
\hline Data analysis and interpretation & $\checkmark$ & -- & $\checkmark$ & -- & -- & $\checkmark$ \\
\hline Writing the article & $\checkmark$ & $\checkmark$ & $\checkmark$ & $\checkmark$ & -- & $\checkmark$ \\
\hline Critical revision of the article & $\checkmark$ & -- & $\checkmark$ & -- & -- & $\checkmark$ \\
\hline Final approval of article & $\checkmark$ & -- & -- & -- & $\checkmark$ & $\checkmark$ \\
\hline Statistical analysis & $\checkmark$ & -- & -- & -- & -- & -- \\
\hline
\end{tabular}

\section{Acknowledgements and Funding}

Amalia Castonguay and Sofia Rivera (Oak Crest Institute of Science) assisted in the collection of vaginal epithelial cells from female volunteers.

Peter A. Anton, M.D. University of California, Los Angeles, CA, contributed editorial and scientific insights to the study.

We would like to especially thank the anonymous volunteers, who donated cells. Without their participation, the study would not have been possible.

Research reported in this publication was supported by the National Institute of Allergy and Infectious Diseases of the National Institutes of Health under Award Number R01Al100744 and U19Al113048. The content is solely the responsibility of the authors and does not necessarily represent the official views of the National Institutes of Health.

\section{Publication history}

Editor: Khin Thway, The Royal Marsden Hospital, UK.

Received: 04-Jan-2020 Final Revised: 18-Mar-2020

Accepted: 28-May-2020 Published: 10-Jun-2020

\section{References}

1. Nicol MR, Fedoriw Y, Mathews M, Prince HM, Patterson KB, Geller E, Mollan K, Mathews S, Kroetz DL and Kashuba AD. Expression of six drug transporters in vaginal, cervical, and colorectal tissues: Implications for drug disposition in HIV prevention. J Clin Pharmacol. 2014; 54:574-83. I Article I PubMed Abstract | PubMed FullText

2. Gunawardana M, Mullen M, Moss JA, Pyles RB, Nusbaum RJ, Patel J, Vincent KL, Wang C, Guo C, Yuan YC, Warden CD and Baum MM. Global expression of molecular transporters in the human vaginal tract: implications for HIV chemoprophylaxis. PLoS One. 2013; 8:e77340. | Article | PubMed Abstract | PubMed FullText 
3. Hu M, Patel SK, Zhou T and Rohan LC. Drug transporters in tissues and cells relevant to sexual transmission of HIV: Implications for drug delivery. J Control Release. 2015; 219:681-696. | Article | PubMed Abstract | PubMed FullText

4. Kis O, Robillard K, Chan GN and Bendayan R. The complexities of antiretroviral drug-drug interactions: role of $A B C$ and SLC transporters. Trends Pharmacol Sci. 2010; 31:22-35. | Article | PubMed

5. Hijazi K, Cuppone AM, Smith K, Stincarelli MA, Ekeruche-Makinde J, De Falco G, Hold GL, Shattock R, Kelly CG, Pozzi G and lannelli F. Expression of Genes for Drug Transporters in the Human Female Genital Tract and Modulatory Effect of Antiretroviral Drugs. PLoS One. 2015; 10:e131405. | Article | PubMed Abstract | PubMed FullText

6. Huang $W$, Zeng $X$, Shi $Y$ and Liu M. Functional characterization of human equilibrative nucleoside transporter 1. Protein Cell. 2017; 8:284-295. | Article | PubMed Abstract | PubMed FullText

7. Abdool Karim $Q$, Abdool Karim SS, Frohlich JA, Grobler AC, Baxter C, Mansoor LE, Kharsany AB, Sibeko S, Mlisana KP, Omar Z, Gengiah TN, Maarschalk S, Arulappan N, Mlotshwa M, Morris L and Taylor D. Effectiveness and safety of tenofovir gel, an antiretroviral microbicide, for the prevention of HIV infection in women. Science. 2010; 329:116874. | Article | PubMed Abstract | PubMed FullText

8. Delany-Moretlwe S, Lombard C, Baron D, Bekker LG, Nkala B, Ahmed K, Sebe M, Brumskine W, Nchabeleng M, Palanee-Philips T, Ntshangase J, Sibiya S, Smith E, Panchia R, Myer L, Schwartz JL, Marzinke M, Morris L, Brown ER, Doncel GF, Gray G and Rees H. Tenofovir 1\% vaginal gel for prevention of HIV-1 infection in women in South Africa (FACTS-001): a phase 3, randomised, double-blind, placebo-controlled trial. Lancet Infect Dis. 2018; 18:1241-1250. | Article | PubMed

9. Kiser PF, Johnson TJ and Clark JT. State of the art in intravaginal ring technology for topical prophylaxis of HIV infection. AIDS Rev. 2012; 14:62-77. | Article | PubMed

10. Romano J, Variano B, Coplan P, Van Roey J, Douville K, Rosenberg Z, Temmerman M, Verstraelen H, Van Bortel L, Weyers S and Mitchnick M. Safety and availability of dapivirine (TMC120) delivered from an intravaginal ring. AIDS Res Hum Retroviruses. 2009; 25:483-8. | Article | PubMed

11. Moss JA, Malone AM, Smith TJ, Kennedy S, Kopin E, Nguyen C, Gilman J, Butkyavichene I, Vincent KL, Motamedi M, Friend DR, Clark MR and Baum MM. Simultaneous delivery of tenofovir and acyclovir via an intravaginal ring. Antimicrob Agents Chemother. 2012; 56:875-82. | Article | PubMed Abstract | PubMed FullText

12. Baum MM, Butkyavichene I, Gilman J, Kennedy S, Kopin E, Malone AM, Nguyen C, Smith TJ, Friend DR, Clark MR and Moss JA. An intravaginal ring for the simultaneous delivery of multiple drugs. J Pharm Sci. 2012; 101:2833-43. | Article | PubMed Abstract | PubMed FullText

13. Lal M, Lai M, Estrada M and Zhu C. Developing a Flexible Pediatric Dosage Form for Antiretroviral Therapy: A Fast-Dissolving Tablet. $J$ Pharm Sci. 2017; 106:2173-2177. | Article | PubMed Abstract | PubMed FullText

14. Chaturvedi A, Srivastava P, Yadav S, Bansal M, Garg G and Sharma PK. Fast dissolving films: a review. Curr Drug Deliv. 2011; 8:373-80. | Article | PubMed

15. Garg S, Goldman D, Krumme M, Rohan LC, Smoot S and Friend DR. Advances in development, scale-up and manufacturing of microbicide gels, films, and tablets. Antiviral Res. 2010; 88 Suppl 1:S19-29. | Article PubMed

16. Panigrahi R and Dash S. ENT1 and treatment of viral diseases. Oncotarget. 2015; 6:32281-2. | Article | PubMed Abstract | PubMed FullText

17. Best KA, Bone DB, Vilas G, Gros R and Hammond JR. Changes in aortic reactivity associated with the loss of equilibrative nucleoside transporter 1 (ENT1) in mice. PLoS One. 2018; 13:e0207198. | Article | PubMed Abstract | PubMed FullText

18. Herbst-Kralovetz MM, Quayle AJ, Ficarra M, Greene S, Rose WA, 2nd, Chesson R, Spagnuolo RA and Pyles RB. Quantification and comparison of toll-like receptor expression and responsiveness in primary and immortalized human female lower genital tract epithelia. Am J Reprod
Immunol. 2008; 59:212-24. | Article | PubMed

19. Rose WA, 2nd, McGowin CL, Spagnuolo RA, Eaves-Pyles TD, Popov VL and Pyles RB. Commensal bacteria modulate innate immune responses of vaginal epithelial cell multilayer cultures. PLoS One. 2012; 7:e32728. | Article | PubMed Abstract | PubMed FullText

20. Boskey ER, Moench TR, Hees PS and Cone RA. A self-sampling method to obtain large volumes of undiluted cervicovaginal secretions. Sex Transm Dis. 2003; 30:107-9. | Article | PubMed

21. Mackey JR, Jennings LL, Clarke ML, Santos CL, Dabbagh L, Vsianska M, Koski SL, Coupland RW, Baldwin SA, Young JD and Cass CE. Immunohistochemical variation of human equilibrative nucleoside transporter 1 protein in primary breast cancers. Clin Cancer Res. 2002; 8:110-6. | Article | PubMed

22. van Genderen IL, van Meer G, Slot JW, Geuze HJ and Voorhout WF. Subcellular localization of Forssman glycolipid in epithelial MDCK cells by immuno-electronmicroscopy after freeze-substitution. J Cell Biol. 1991; 115:1009-19. | Article | PubMed Abstract | PubMed FullText

23. Griffiths $G$. Fine structure immunocytochemistry. Springer Science \& Business Media. 2012.

24. Gundersen HJ, Bendtsen TF, Korbo L, Marcussen N, Moller A, Nielsen K, Nyengaard JR, Pakkenberg B, Sorensen FB, Vesterby A and et al. Some new, simple and efficient stereological methods and their use in pathological research and diagnosis. APMIS. 1988; 96:379-94. | Article | PubMed

25. Tschanz SA, Burri PH and Weibel ER. A simple tool for stereological assessment of digital images: the STEPanizer. J Microsc. 2011; 243:4759. | Article | PubMed

26. Baddeley AJ, Gundersen $\mathrm{HJ}$ and Cruz-Orive LM. Estimation of surface area from vertical sections. J Microsc. 1986; 142:259-76. | Article | PubMed

27. Cerveny L, Ptackova Z, Ceckova M, Karahoda R, Karbanova S, Jiraskova L, Greenwood SL, Glazier JD and Staud F. Equilibrative Nucleoside Transporter 1 (ENT1, SLC29A1) Facilitates Transfer of the Antiretroviral Drug Abacavir across the Placenta. Drug Metab Dispos. 2018; 46:18171826. | Article | PubMed

28. Boswell-Casteel RC and Hays FA. Equilibrative nucleoside transporters, A review. Nucleosides, Nucleotides and Nucleic Acids. 2017; 36:7-30.

29. Anderson DJ, Marathe J and Pudney J. The structure of the human vaginal stratum corneum and its role in immune defense. Am J Reprod Immunol. 2014; 71:618-23. | Article | PubMed Abstract | PubMed FullText

30. Benicky J, Hafko R, Sanchez-Lemus E, Aguilera G and Saavedra JM. Six commercially available angiotensin II AT1 receptor antibodies are non-specific. Cell Mol Neurobiol. 2012; 32:1353-65. | Article | PubMed Abstract | PubMed FullText

31. Bordeaux J, Welsh A, Agarwal S, Killiam E, Baquero M, Hanna J, Anagnostou V and Rimm D. Antibody validation. Biotechniques. 2010; 48:197-209. | Article | PubMed Abstract | PubMed FullText

32. Couchman JR. Commercial antibodies: the good, bad, and really ugly. J Histochem Cytochem. 2009; 57:7-8. | Article | PubMed Abstract | PubMed FullText

33. Saper CB. A guide to the perplexed on the specificity of antibodies. J Histochem Cytochem. 2009; 57:1-5. | Article | PubMed Abstract | PubMed FullText

34. Hewitt SM, Baskin DG, Frevert CW, Stahl WL and Rosa-Molinar E. Controls for immunohistochemistry: the Histochemical Society's standards of practice for validation of immunohistochemical assays. J Histochem Cytochem. 2014; 62:693-7. | Article | PubMed Abstract | PubMed FullText

35. Griffiths $\mathrm{G}$ and Lucocq JM. Antibodies for immunolabeling by light and electron microscopy: not for the faint hearted. Histochem Cell Biol. 2014; 142:347-60. | Article | PubMed Abstract | PubMed FullText

36. Howat WJ, Lewis A, Jones P, Kampf C, Ponten F, van der Loos $\mathrm{CM}$, Gray N, Womack C and Warford A. Antibody validation of immunohistochemistry for biomarker discovery: recommendations of a consortium of academic and pharmaceutical based histopathology 
Webster et al., Journal of Histology \& Histopathology 2020,

http://www.hoajonline.com/journals/pdf/2055-091X-7-5.pdf

researchers. Methods. 2014; 70:34-8. | Article | PubMed Abstract | PubMed FullText

37. Medina-Colorado AA, Vincent KL, Miller AL, Maxwell CA, Dawson LN, Olive T, Kozlova EV, Baum MM and Pyles RB. Vaginal ecosystem modeling of growth patterns of anaerobic bacteria in microaerophilic conditions. Anaerobe. 2017; 45:10-18. | Article | PubMed Abstract | PubMed FullText

38. Herbst-Kralovetz MM, Pyles RB, Ratner AJ, Sycuro LK and Mitchell C. New Systems for Studying Intercellular Interactions in Bacterial Vaginosis. $J$ Infect Dis. 2016; 214 Suppl 1:S6-S13. | Article | PubMed Abstract | PubMed FullText

39. Averette HE, Weinstein GD and Frost P. Autoradiographic analysis of cell proliferation kinetics in human genital tissues. I. Normal cervix and vagina. Am J Obstet Gynecol. 1970; 108:8-17. | Article I PubMed

40. Patton DL, Thwin SS, Meier A, Hooton TM, Stapleton AE and Eschenbach DA. Epithelial cell layer thickness and immune cell populations in the normal human vagina at different stages of the menstrual cycle. Am J Obstet Gynecol. 2000; 183:967-73. | Article | PubMed

\section{Citation:}

Webster P, Cortez J, Webster S, Gunawardana M, Pyles RB and Baum MM. Equilibrative nucleoside transporter 1 (slc29a1) localization on vaginal epithelial cells. J Histol Histopathol. 2020; 7:5. http://dx.doi.org/10.7243/2055-091X-7-5 